IOSR Journal of Engineering

Apr. 2012, Vol. 2(4) pp: 777-780

\title{
Flammability properties of low density polyethylene/wood fibre composites
}

\author{
M. U. Obidiegwu. \\ Department of Polymer and Textile Engineering \\ Federal University of Technology P.M.B 1526, Owerri, Imo State, Nigeria.
}

\begin{abstract}
Using simple combustion apparatus the effect of wood fibres on the flammability properties of Low Density Polyethylene (LDPE) was studied. Composite samples were prepared with LDPE and Kola Nitida (KN), and LDPE and Alstonia Boonei (AB) with fibre contents of $0,5,10,15$, and $20 \mathrm{wt} . \%$. Test results show that ignition time and time for auto-combustion increased with increasing fibre content for both composite types. The flame propagation rate decreased with increasing fibre content for both composite samples. At 20 wt. $\%$, LDPE/KN had about $650 \%$ and $1032 \%$ increment in ignition time and auto combustion time respectively, and showed a decrease of about $200 \%$ in FPR value, while LDPE/AB had about $290 \%$ and $180 \%$ increment in ignition time and auto combustion time respectively, and showed a decrease of about $110 \%$ in FPR value. The results show that LDPE/KN composites show better flame retardancy properties over LDPE/AB composites at $20 \mathrm{wt} \%$ fibre content.
\end{abstract}

Key words: Flammability, composite, low density polyethylene, kola nitida, alstonia boonei

\section{Introduction}

Polyethylene remains one of the most useful polymers. As a thermoplastic, it could be re-shaped, re-used, repaired, and recycled as the need arises. Though its usefulness predisposes it to a variety of applications in almost every part of our daily lives, it has a high potential to act as fuel in the face of fire just like most hydrocarbons.

Hydrocarbons are basically fuels. According to the statistical relationship derived by Charniwalla and Parik, (2002), the higher heating value of fuels depends positively on their hydrocarbon content.

$$
\begin{aligned}
& H H V_{\text {fuel }}=0.3491 z_{C}+1.1783 z_{H}-0.1034 z_{O} \\
& -0.0151 z_{N}+0.1005 z_{S}-0.0211 z_{A}
\end{aligned}
$$

Where $H H V_{f \text { wal }}$ is the Higher Heating Value of fuel in $\mathrm{MJ} / \mathrm{Kg}, z_{C}, z_{H_{s}}, z_{O}, z_{N_{s}} z_{S_{2}}$ and $z_{A}$ are the weight fraction of carbon, hydrogen, oxygen, sulphur, and ashes respectively. Therefore, polymers with less oxygen, nitrogen, and ash contents have higher heating values and ease of combustion. Polyethylene unfortunately, is comprised mainly of only hydrogen and carbon, hence, the risk of supporting combustion is very high.

The combustion of polymers follows a pattern. First, the polymer in the presence of a flame source is pre-heated. During preheating, the polymer decomposes and releases gaseous hydrocarbons into the atmosphere around the flame source. These hydrocarbons at the appropriate temperature becomes ignited and consequently combust in oxygen to release heat (Cullis and Hirschler, 1981). Although most of the heat is lost to the environment in which combustion is taking place, a fraction finds its way back to the polymer and then pre-heats, decomposes, ignites, and combusts the polymer. Hence, the cycle continues. Disrupting this cycle

would relatively inhibit combustion. Different methods have been employed and they aim at increasing either the ignition time, or the time before which the polymer sample begins to generate fire on its own without an external heat source (i.e., auto-combusting) (Stark et al., 2010; Gerad et al., 2010). Or reducing the flame propagation rate (i.e., rate of spread of fire) (Nelson, 1995). Interrupting the fire cycle can be achieved in either of the three ways;(i) modifying the polymer to produce less flammable gases, (ii) inhibiting burning or quenching flame, (iii) reducing the feedback heat from the flame to the decomposing polymer (Mark, 1978). Based on these, many flame retardants have been developed.

Flame retardants incorporated into polymers can successfully extinguish fire either in the gaseous or solid phase, because flammability is a function of both solid and gas phase chemistry (Nelson, 1995). In the solid phase, the flame retardants can cause the formation of a large flameresistant carbon compound (char or ash) over the polymer surface. This foamed surface is heat resistant, and can soak up the heat being fed back (Weil, 1992), consequently smothering the burning polymer. In the gaseous phase, flame retardants produce non-combustible gases which attack the fire propagating free radicals to produce relatively stable, non-combustible free radicals (Hilado, 1998).

Many chemicals have been used to improve the flame resistance of polymers. Halogenated flame retardants may either function in gaseous or solid phase (Hilado, 1982). Bromine-based retardants acts in the gaseous phase to redirect or terminate chemical reactions, (Hilado, 1998). Phosphorus flame retardants include a wide variety of phosphate compounds: elemental red phosphorus, watersoluble inorganic phosphates, insoluble ammonium polyphosphate, organophosphates and phosphonates, phosphine oxides, and chloroaliphatic and bromoaromatic phosphates(Green, 2000). Vinyl and allyl phosphonates are very reactive flame retardants (Allen, 1993). Phosphorouscontaining polyols have been used extensively in the polyurethane industry(Lee et al., 1982). Phosphorous containing nitrogens or halogens have been used as flame 
retardants (Green, 1994; Inoue et al., 1989 ). The presence of nitrogen compounds have had significant effect on flame resistance, as can be seen in the low flammability of wool, silk, and leather (Horacek and Grabner, 1996), triazines, isocyanates, urea, guanidine, and cyanuric acid derivatives are nitrogen-containing organic compounds and have been used as flame retardants (Horacek and Grabner, 1993). Silicon containing flame retardants have also been used ( $\mathrm{Iji}$, 1998; Zaikov and Lomakin, 1996). Boron-based compounds have also received extensive usage (Zing de, 1996). Although the polymer in which these flame retardants have been added show improved flame resistance, nevertheless during combustion, most of these flame retardants release toxic gases into the atmosphere. This can be potentially harmful to the environment.

Reinforcing polymers with wood fibres have attracted increasing research activities. Besides offering improved mechanical properties, they reduce the amount of polymer resin used. This reduces the percentage of nonbiodegradable Low Density Polyethylene in the environment. Furthermore, wood fibres are readily available, and relatively easy to procure and process. Since wood fibres are basically natural, their combustion products would be $\mathrm{CO}_{2}$ and $\mathrm{H}_{2} \mathrm{O}$, and this could be recycled through photosynthesis to produce bio-matter. Wood fibres therefore do not 'add' to the already available quantity of $\mathrm{CO}_{2}$ in the atmosphere during combustion, hence they are carbon 'neutral' and eco friendly. However, the fire performance of the composites has received limited attention in the literature (Stark et al., 2010). This research work investigates and compares the effects of Kola Nitida (kola nut tree) and Alstonia Boonei (dogon yaro tree), plants denizen in the West Africa with a massive annual production, on the flammability properties of Low Density Polyethylene.

\section{0 materials and methods \\ 2.1 MATERIALS}

Low Density Polyethylene was gotten from CEEPLAST Industry Ltd., Adaelu Street, Osissioma Industrial Layout, Aba, Abia State, Nigeria. Kola nut stem bark was obtained from Kola Nitida plant. Alstonia boonei stem bark was obtained from the plant. They were both gotten from a local farm in Ahiazu Mbaise, Imo State, Nigeria. The stem barks were dried for three weeks, and then pulverized into powder form. The powdered fibres were then sieved with $0.3 \mathrm{~mm}$ mesh size at the Corrosion Control Laboratory, Federal University of Technology Owerri, Imo State, Nigeria, and then dried in a dessicator.

\subsection{COMPOSITE PREPARATION}

Composite samples were prepared with LDPE/wood fibres using formulations of varying fibre contents from $0-20$ wt \% . Powdered samples of LDPE and $\mathrm{KN}$ and $\mathrm{AB}$ at varying weight contents were fed into an injection moulding machine to produce compounded composite samples. The injection moulding was done by the injection moulding machine in the Department of Polymer and Textile Engineering, Federal University of Technology, Owerri, Imo State, Nigeria was used. Sample formulations are given in Table 3.1 .

Table 3.1 SAMPLE FORMULATION

\begin{tabular}{|l|l|l|}
\hline Samples & $\begin{array}{l}\text { Kola nut (Stem bark } \\
\text { wt.\%) }\end{array}$ & $\begin{array}{l}\text { LDPE } \\
(\text { wt. } \%)\end{array}$ \\
\hline LDPE & & 100 \\
\hline KN1 & 5 & 95 \\
\hline KN2 & 10 & 90 \\
\hline KN3 & 15 & 85 \\
\hline KN4 & 20 & 80 \\
\hline Samples & $\begin{array}{l}\text { Alstonia Boonei (stem } \\
\text { bark wt.\%) }\end{array}$ & $\begin{array}{l}\text { LDPE } \\
(\text { wt } \%)\end{array}$ \\
\hline AB1 & 5 & 95 \\
\hline AB2 & 10 & 90 \\
\hline AB3 & 15 & 85 \\
\hline AB4 & 20 & 80 \\
\hline
\end{tabular}

\subsection{FLAMMABILITY TESTS}

The following flammability tests were carried out in the Laboratory of the Department of Polymer and Textile Engineering, Federal University of Technology Owerri, Imo State, Nigeria.

\subsection{1:IGNITIONTIME}

Composite samples were held by a retort stand over the heat source at a constant distance. The ignition time was recorded as the time between the initial supply of flame from the heat source and the appearance of flame on the sample.

\subsection{2:AUTO-COMBUSTINGTIME}

Samples were held by a retort stand at a constant distance over a heat source. The auto-combusting time was recorded as the time that elapsed between an initial supply of flame and self-sustaining combustion of composite samples.

\subsection{3: flame propagation rate}

The rate of spread of fire was recorded as the flame propagation rate. Composite samples were held by a retort stand at a constant distance over a heat source. Test samples were marked $\mathrm{X}$, a distance $3 \mathrm{~cm}$ from the end just above the flame source. The Flame Propagation Time (FPT) was recorded as the time between an initial supply of flame and the combustion of the X mark. Flame Propagation Rate (FPR) is the ratio of the distance from the sample end (i.e., $3 \mathrm{~cm}$ ) and the flame propagation time.

$$
F P R=\frac{x}{F P T} \quad 2.1
$$

\subsection{RESULTS AND DISCUSSION}

The results obtained are presented in Table 3.1. The ignition time of test samples increased with increasing fibre content for both composite types. For LDPE/KN, ignition 
time became longer at higher fibre content (i.e., 15 and 20 wt. \%), while LDPE/AB showed a rather stable increment with increasing fibre content. This increment in ignition time show that the reinforcement of LDPE by KN produce better flame resistant properties with over $600 \%$ increase in ignition time over $100 \mathrm{wt}$ \% LDPE sample at $20 \mathrm{wt} \%$.

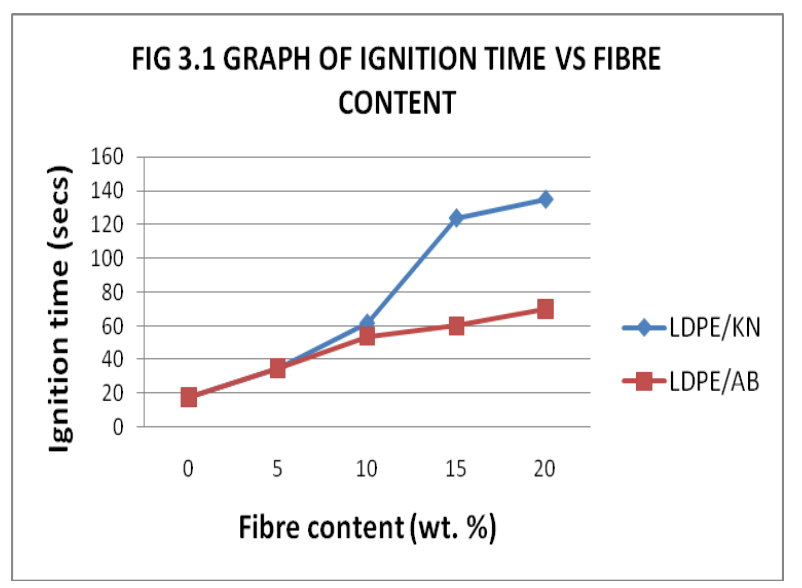

The results of the auto-combusting time are presented in Fig 3.2. The time before the sample became autocombusting increased with increasing fibre content for both composite types. Again LDPE/KN showed better resistance to burning, producing a value of over $1000 \%$ at $20 \mathrm{wt}$. \% over 100 wt. \% LDPE sample.

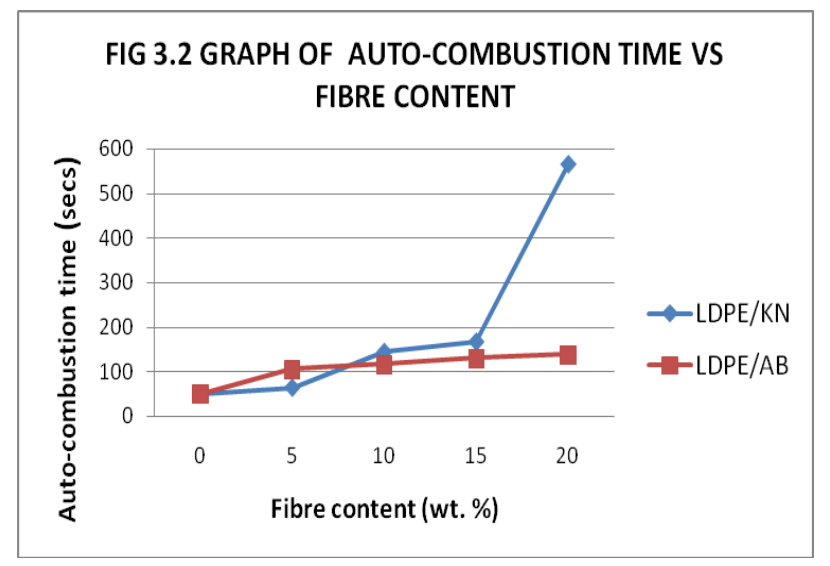

The Flame Propagation Rate (FPR) further corroborates the flame retardancy properties of the wood fibres. The results presented in Fig 3.3 show that the rate of flame propagation decreased with increasing fibre content for both composite samples. This shows that the rate of spread of the flame reduced with increasing fibre content. LDPE/KN showed

\section{References}

1. O’Driscoll, M., Ind. Minerals, 1994, 318, p. 23.

2. Hilado, C.J., Flammability Handbook for Plastics, 3rd ed., Technomic Publication, Westport, CT, 1982.

3. Green, J., In Fire Retardancy of Polymeric Materials, Wilkie, C.A., ed., Marcel Dekker Inc., New York, 2000, p. 147. the lowest value which is about $200 \%$ reduction in FPR in comparison to $100 \mathrm{wt} . \% \mathrm{LDPE}$ at $20 \mathrm{wt} \%$ fibre content.

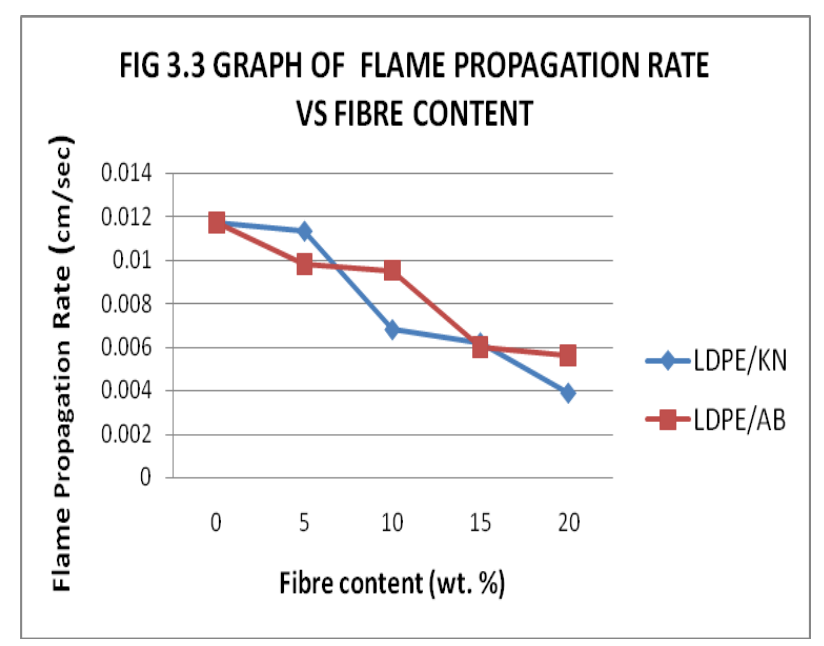

The different test results show that at low fibre content, the flammability resistance of both composite types did not differ much, but at higher fibre content the effect of $\mathrm{KN}$ became pronounced.

The polymer apparently became relatively resistant to ignition, sustain combustion, and propagation of flame with increasing fibre content. This suggests that the composite samples became resistant to decomposition, thereby making it impossible to support burning and increasing the ignition time. Also, The presence of wood fibres contain substantial amount of oxygen and ash, and according to equation 1.1, this reduces the higher heating value, and consequently, the combustibility of the composite.

\section{Conclusion}

Test results show that the flame resistance of LDPE could be increased by reinforcement with wood. Ignition time and auto-combusting time were increased when LDPE was reinforced with $\mathrm{KN}$ and $\mathrm{AB}$. LDPE/KN produced ignition time and auto-combustion time at $20 \mathrm{wt} \%$ fibre content. Also, the FPR of LDPE was considerably reduced when reinforced with $\mathrm{KN}$ and $\mathrm{AB}$. Low Density Polyethylene reinforced with Kola Nitida show better flame retardancy properties compared with Alstonia Boonei.

4. Lee, F.T., Green, J., and Gibilisco, R.D., J. Fire Retard. Chem., 1982, 9, p. 232.

5. Allen, C.W., J. Fire Sci., 1993, 11, p. 320.

6. Green, J.J., Fire Sci., 1994, 12, p. 257.

7. Inoue, K., Nakamura, H., Ariyoshi, S., Takagi, M., and Tanigaki, T., Macromolecules, 1989, 22, p. 4466. 
IOSR Journal of Engineering

Apr. 2012, Vol. 2(4) pp: 777-780

8. Montaudo, G., Scamporrino, E., and Vitalini, D., J. Polym. Sci. Part A: Polym. Chem., 1983, 21, p. 3321.

9. Horacek, H. and Grabner, R., Polym. Degrad. and Stability, 1996, 54, p. 205.

10. Horacek, H. and Grabner, W., Makromol. Chem., Macromol. Symp., 1993, 74, p. 271.

11. Iji, M. and Serizawa, S., Polym. Adv. Technol., 1998, 9, p. 593.

12. Kambour, R.P., Klopper, H.J., and Smith, S.A., J. Appli. Polym. Sci., 1981, 26, p. 847.

13. Zaikov, G.E. and Lomakin, S.M., Polym. Degrad. Stabil., 1996, 54, p. 223.

14. Allen, N.S., Edge, M., and Corrales, T., Polym. Degrad. Stabil. 1997, 56, p. 125.

15. Chao, T.C., Sarmah, S.K., Boisvert, R.P., Burns, G.T., Katsoulis, D.E., and Page, W.C., In Proceedings of 43rd International SAMPE Symposium, Anaheim, 1998, pp. 1029-1041.

16. Bolf, A.G. and Lichtenhan, J.D., Am. Chem. Soc. Polym. Prepr, 1994, 35, pp. 527-528.

17. Gilman, J.W., Jackson, C.L., and Morgan, A.B., Chem. Mater, 2000, 12, pp. 1866-1873.

18. Giannelis, E.P., Adv. Mater., 1996, 8, p. 29.

19. Allen, C.W., Trends in Polymer Science, 1994, 2, p. 342.

20. Mark, J.E., Allcock, H.R., and West, R., Inorganic Polymers, Prentice Hall, New Jersey, 1992.

21. Zingde, G., In ANTEC Technical Conference Proceedings, 1996, 54 (3), p. 3004. 